\title{
Analysis of Expert System Investment Technology Based on Software Sector
}

\author{
Hui Ma \\ Guangxi College of Education, Nanning 530023, Guangxi, China \\ 1040168586@qq.com \\ ${ }^{*}$ Corresponding author: Hui Ma
}

\begin{abstract}
With the winning ratio, annual return rate and net profit rate as the management goals, the practicality of the RSI and MA expert systems for the software sector is analyzed. The winning rate of the RSI expert system is $54.05 \%, 1.35$ times that of the MA expert system. The annual return rate and net profit rate of the RSI expert systems are $1.22 \%$ and $2.24 \%$ respectively, 6.33 times and 11.61 times that of the MA expert system. The number of annual transactions of the RSI expert system is 0.60 times that of the MA expert system. Frequent trading of the MA expert system is the main reason for its cost increase. This results show that the RSI expert system is significantly superior to the MA expert system. Considering the low annual return rate and net profit rate of the RSI expert system, compared with the banking sector, the selection of the sector is more important than the selection of the expert system.
\end{abstract}

Keywords: Software Sector, RSI Expert System, MA Expert System.

\section{Introduction}

In financial transactions, technical analysis is one of the more popular methods. Software commonly used in technical analysis is accompanied by an expert system. Yu Fang et al. studied the most commonly used moving average (MA) expert system and the anti-trend right scale integration (RSI) expert system [1] and obtained the conclusion that the RSI expert system was significantly superior to the MA expert system in terms of winning rate, annual return rate and net profit rate in addition to the number of annual transactions. Yu Fang et al. also studied the anti-trend expert systems RSI, BIAS, KDJ and W\&R[2] and concluded that the RSI expert system was the best and the W\&R expert system was the worst in terms of annual return rate and net profit rate. RSI's net profit rate and annual return rate are nearly 5 times better than W\&R, BIAS expert system's winning rate is the highest, up to $98.54 \%$, and W\&R's number of annual transactions is the highest, up to 7,658.40. Now, with annual return rate, winning rate and net profit rate as the management targets, taking the banking sector of listed companies as a sample, an empirical analysis is conducted using MA and RSI expert systems as the analysis tools.

RSI (Relative Strength Index) mathematical formula [3]:

$$
\begin{aligned}
& R S I=\frac{100 \times R S}{1+R S} \\
& R S=\frac{\text { Average Rise Point in i days }}{\text { Average Dropped Point in i days }}(i=1,2, \mathrm{~L} n)
\end{aligned}
$$

The formula of the moving average Ma [4] is:

$$
M A=\frac{c_{1}+c_{2}+\mathrm{L} \mathrm{L}+c_{n}}{n}
$$

Where, $c_{i}(i=1,2, \mathrm{~L} n)$ is the $\mathrm{i}$-th day of closing price, and $n$ is the moving average cycle. 


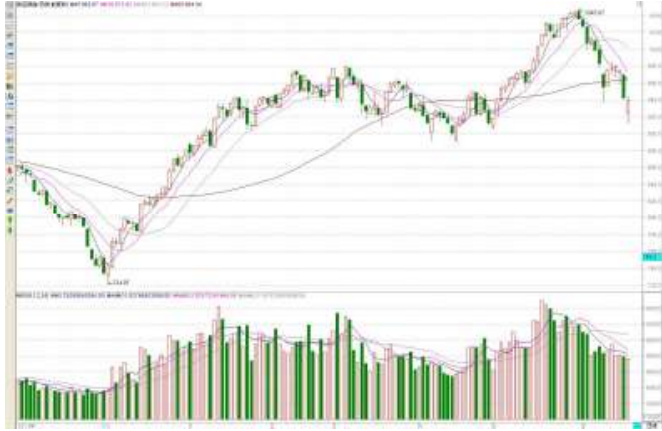

Figure 1 MA Expert System

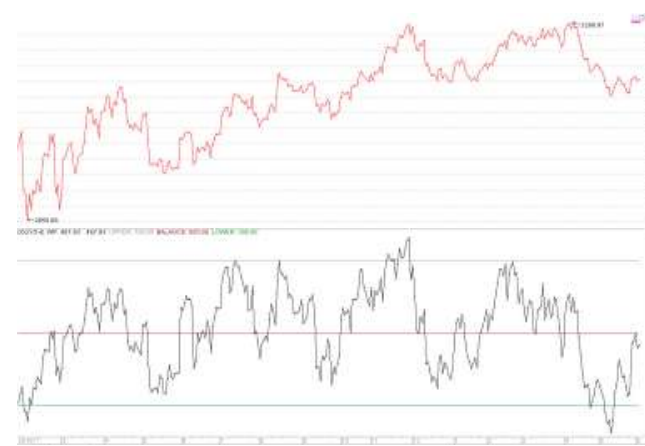

Figure 2 RSI Expert System

Empirical Analysis Based on RSI expert system (shown in figure 2) and MA expert system (see Fig.1)

Experiment and Results

(1) Experimental procedures

Expert system RSI is formulated based on the rule by Welles Wilder. The buying and selling rule is: buying when RSI (14) varies from 0 to 20 or from 50 to 80, selling RSI (14) varies from 80 to 100 , and waiting and seeing when RSI (14) varies from 20 to 50[5]

Source code of RSI expert system

N1 110014

LL 04020

LH 6010080

LC: $=$ REF (CLOSE, 1);

RSI:SMA(MAX(CLOSE-LC,0),N1,1)/SMA(ABS(CLOSE-LC),N1,1)*100,colorwhite; ENTERLONG: CROSS (RSI, LL);

EXITLONG: CROSS (LH, RSI)

The expert system MA is developed in accordance with Granville's eight rules. The transaction rule is: $\mathrm{MA}(10)$ line is added to $\mathrm{MA}(5)$ line to form the golden cross buy-in. MA(30) line is destroyed by MA(10) line to form the death cross sell-out [6].

Source code of the MA expert system

SHORT 1305

LONG 510030

CROSS(MA(CLOSE,SHORT),MA(CLOSE,LONG))

CROSS(MA(CLOSE,LONG),MA(CLOSE,SHORT))

ENTERLONG:CROSS(MA(CLOSE,SHORT),MA(CLOSE,LONG));

EXITLONG:CROSS(MA(CLOSE,LONG),MA(CLOSE,SHORT))

(2) Experimental platform: great wisdom securities information platform V5.99 version

(3) Experimental parameters: to open a position once or close all positions when conditions are met. Transaction costs take $0.5 \%$.

(4) Experimental sample: daily data of vocational education sector (May 2016 through March 2018)

(5) Experimental process, time and results:

Table 1 Test Results Based on MA Expert System

Test method: Stock Selection Formula - MA Buy

\section{System Test Settings}

Test Time: 2016-5-18 - 2018-3-30 Excluding forced liquidation

Test Stocks: A total of 181 stocks Initial Investment: RMB 20,000.00

Buying conditions:

One of the following groups is established:

1. The following conditions are established at the same time

1.1 Stock Selection Formula: MA buy $(5,10)$ [date line] 
When the conditions are met: In accordance with the middle price: Buy at full price using the closing price:

When there is a continuous signal: no longer buy

Selling conditions: no selling conditions

Closing conditions: (Closed at the closing price)

Index selection: stock selection formula: MA sell $(10,30)$ [date line]

Test Stocks: 181

Annual return rate: $-5.11 \% \quad$ Number of annual transactions: 613.64

Winning rate: $40.00 \% \quad$ Success rate: $38.96 \%$

Average profit: RMB -301.60 Annual average signal quantity: 1,345.09 times

Maximum single profit: RMB 13,652.38 Maximum single loss: RMB -14,088.60

Number of transactions: 1125

Net profit: RMB -339,297.50

Profitable transactions: $450(40.00 \%)$

Net profit rate: $-9.37 \%$

Simple holding net profit: RMB 2,613,696.25 Simple holding net profit rate: $72.20 \%$

Ideal model net profit: RMB 8.124243777997056E21

Ideal model net profit rate: $224,426,626,924,937,216.00 \%$

Analysis of Results

Table2 Comparative Analysis Sheet

\begin{tabular}{|c|c|c|c|c|}
\hline & Win Rate & $\begin{array}{c}\text { Annual Rate of } \\
\text { Return }\end{array}$ & Net Profit Margin & $\begin{array}{c}\text { Annual } \\
\text { Transaction Times }\end{array}$ \\
\hline $\begin{array}{c}\text { RSI Expert } \\
\text { System }\end{array}$ & 54.05 & 1.22 & 2.24 & 370.36 \\
\hline $\begin{array}{c}\text { MA Expert } \\
\text { System }\end{array}$ & 40.00 & -5.11 & -9.37 & 613.64 \\
\hline $\begin{array}{l}\text { Ratio of RSI } \\
\text { results to MA } \\
\text { results }\end{array}$ & $135 \%$ & $633 \%$ & $1161 \%$ & $60.35 \%$ \\
\hline
\end{tabular}

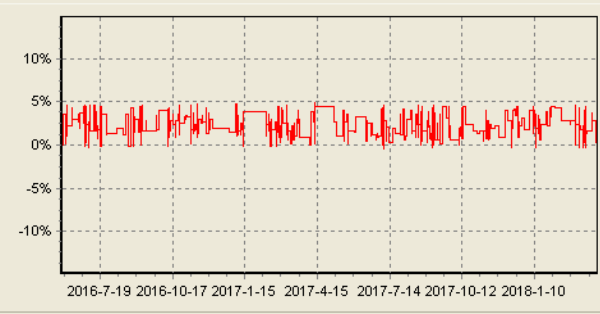

Figure 3 RSI Yield Curve

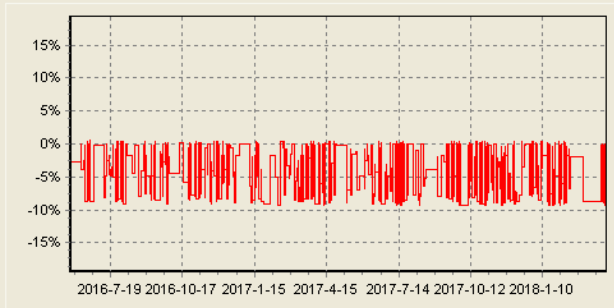

Figure 5 MA Yield Curve

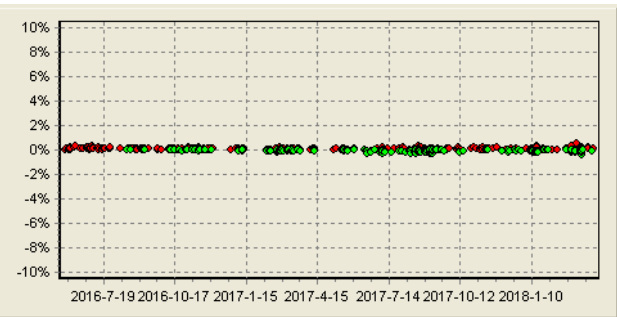

Figure 4 Annual RSI Transaction Times

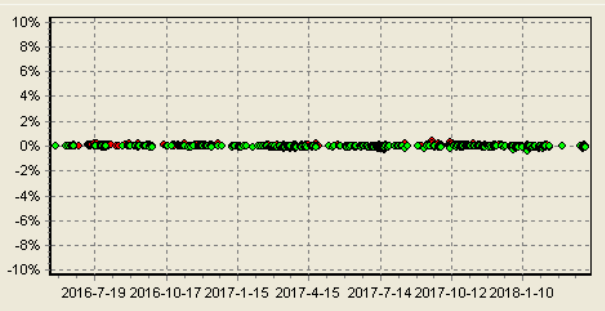

Figure 6 Annual MA Transaction Times 


\section{Conclusion}

This paper analyzes the practicality of the RSI and MA expert systems for the software sector with wining rate, annual return rate and net profit rate that investors care most about as the management goals [7-8]. The winning rate of the RSI expert system is $54.05 \%, 1.35$ times that of the MA expert system. The RSI expert system is clearly acceptable for risk-like investors, and the risks of the MA expert system are highlighted. The annual return rate and net profit rate of the RSI expert system are $1.22 \%$ and $2.24 \%$ respectively, much lower than the bank's interest for the same period and 6.33 times and 11.61 times that of the MA expert system. This results show that the RSI expert system is significantly superior to the MA expert system. The number of annual transactions of the RSI expert system is 0.60 times that of the MA expert system. Frequent trading of the MA expert system is the main reason for its cost increase. Considering the low annual return rate and net profit rate of the RSI expert system, neither of the two systems is attractive for any investor. Compared with the banking sector (the annual return rate and net profit rate of the RSI are $16.62 \%$ and $15.23 \%$ respectively over the same period), the selection of the sector is more important than the selection of the expert system.

\section{Acknowledgement}

The study was supported by the following units: Guangxi Education Science "Twelfth Five-Year Plan" Project Topic "Research on the Status and Countermeasures of Rural Mathematics Teachers' Teaching Ability in Guangxi Province”, Project No.: 2013C109; Guangxi College of Education 2014 Effective Education Project "Research and Practice on the Cultivation of Classroom Teaching Skills of Primary School Mathematics Effective Education for Normal School Students".

\section{References}

[1] Fang Yu: "Empirical Analysis of RSI Based on Vocational Education Sector of Listed Companies", Advances in Computer Science Research, 81(2017) 237-240

[2] H. P. HUANG, P. WANG: "Discussions on Securities Software Expert System MA and RSI", Advanced Materials Research, 798-799 (2013)757-760

[3] Z. H. Lin: "MA Empirical Analysis Based on the Cloud Computing Sector of Listed Companies", Advances in Computer Science Research, 81(2017)269-273

[4] P. WANG, H. P. HUANG: "On the W\&R and RSI Expert Systems of Securities Software", Applied Mechanics and Materials, 433-435(2013)1685-1688

[5] H. P. HUANG, P. WANG: "Analyses on W\&R and BIAS Expert System of Stock-market Software", Applied Mechanics and Materials, 433-435(2013)2391-2394

[6] Information on http://en.wikipedia.org/wiki/Relative_strength_index

[7] WANG Pin "RSI Investment Decision-Making Based on Consolidation Market" Journal of Quantitative Economics 01 (2012) 25-29

[8] HUANG Hai-ping, WANG Pin "Discussions on Securities Software Expert System MA and RSI" Advanced Materials Research 798-799 (2013) 757-760 